\title{
PF Regimen
}

National Cancer Institute

\section{Source}

National Cancer Institute. PFRegimen. NCI Thesaurus. Code C63682.

A regimen consisting of cisplatin and continuous infusion fluorouracil used as either induction (neoadjuvant) therapy or concurrently with radiation (chemoradiation), for the treatment of squamous cell head and neck carcinoma and nasopharyngeal cancer; also used alone for the treatment of unresectable and recurrent head and neck carcinoma. 